\title{
Mechanism of tanshinones and phenolic acids from Danshen in the treatment of coronary heart disease based on co- expression network
}

\author{
Dongxue Wu, Mengqi Huo, Xi Chen, Yanling Zhang ${ }^{*}$ and Yanjiang Qiao*
}

\begin{abstract}
Background: The tanshinones and phenolic acids in Salvia miltiorrhiza (also named Danshen) have been confirmed for the treatment of coronary heart disease (CHD), but the action mechanisms remain elusive.

Methods: In the current study, the co-expression protein interaction network (Ce-PIN) was used to illustrate the differences between the tanshinones and phenolic acids of Danshen in the treatment of CHD. By integrating the gene expression profile data and protein-protein interactions (PPIs) data, the Ce-PINs of tanshinones and phenolic acids were constructed. Then, the Ce-PINs were analyzed by gene ontology enrichment analyzed based on the optimal algorithm.

Results: It turned out that Danshen is able to treat CHD by regulating the blood circulation, immune response and lipid metabolism. However, phenolic acids may regulate the blood circulation by Extracellular calcium-sensing receptor (CaSR), Endothelin-1 receptor (EDNRA), Endothelin-1 receptor (EDNRB), Kininogen-1 (KNG1), tanshinones may regulate the blood circulation by Guanylate cyclase soluble subunit alpha-1 (GUCY1A3) and Guanylate cyclase soluble subunit beta-1 (GUCY1B3). In addition, both the phenolic acids and tanshinones may regulate the immune response or inflammation by T-cell surface glycoprotein CD4 (CD4), Receptor-type tyrosine-protein phosphatase C (PTPRC).

Conclusion: Through the same targets of the same biological process and different targets of the same biological process, the tanshinones and phenolic acids synergistically treat coronary heart disease.
\end{abstract}

Keywords: Coronary heart disease, Danshen, Co-expression network

\section{Background}

CHD is one of the ten leading diseases all over the world [1]. According to the World Health Organization, Coronary heart disease causes more than 700,000 deaths each year in China [2], which involves in thrombus formations [3], inflammation process [4], myocardial ischemia [5], etc. Traditional Chinese medicine (TCM) can treat the CHD by the synergistic effect of various components at a systemic level [6,7]. Especially the blood stasis medicine, has been used for treating the

* Correspondence: zhangyanling@bucm.edu.cn; yjaiao@bucm.edu.cn Beijing University of Chinese Medicine, State Administration of Traditional Chinese Medicine, Research Center of TCM-Information Engineering, Beijing 100102, China

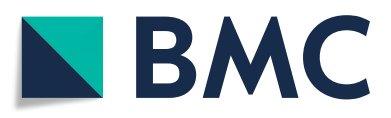

(c) The Author(s). 2020 Open Access This article is distributed under the terms of the Creative Commons Attribution 4.0 International License (http://creativecommons.org/licenses/by/4.0/), which permits unrestricted use, distribution, and reproduction in any medium, provided you give appropriate credit to the original author(s) and the source, provide a link to the Creative Commons license, and indicate if changes were made. The Creative Commons Public Domain Dedication waiver (http://creativecommons.org/publicdomain/zero/1.0/) applies to the data made available in this article, unless otherwise stated. 
phenolic acids of Danshen have antioxidant, antiinflammatory, inhibition of platelet aggregation, antithrombosis and so on [14-17]. However, the study of the difference between the tanshinones and phenolic acids of Danshen focused on specific activities, such as antimicrobial activity [18]. In this study, we will illustrate the holistic difference between tanshinones and phenolic acids for the treatment of coronary heart disease at the molecular level.

Proteins are vital macromolecules, which interact with each other to induce the biological function in an organism. Therefore, protein interaction network (PIN) could provide the basis of understanding cellular organization and processes. Recently, application of high-throughput technologies produces a large amount of protein interaction data, but the interactions cannot be directly used to identify signaling pathways or active networks [19]. The high-throughput sequencing analysis of gene expression has become increasingly valued as a promising tool for analyzing the molecular mechanism of formulas and the discovery of new anticancer targeted drugs $[20,21]$. Thus, the combination of gene expression profiles and protein network information is more likely to be correct than date source alone for illustrating the mechanisms underlying the observed changes in activity of a biological process [22]. The PIN integrated with gene expression profile called the co-expression protein interaction network (Ce-PIN) has been used in the identification of a hub protein [23], elaborating the molecular mechanism of cancer [24]. And Ce-PIN has not been used in the study of tanshinones and phenolic acids mechanism for the treatment of other diseases.

In this study, the PINs were integrated with CHD gene expression profile from GEO to constructed the Ce-PIN; afterwards the Ce-PINs were analyzed by gene ontology enrichment analyzed based on the optimal algorithm. This research aimed at providing a novel approach to study treatment mechanisms of Danshen systematically and compare the difference between tanshinones and phenolic acids in treatment for CHD.

\section{Methods}

\section{Data mining}

The main active components of Danshen will be used to study the mechanism of Danshen in treating coronary heart disease. By literature retrieval, the main active components of Danshen were selected based on the principles that components are the main efficacy compounds and has the effect of treating $\mathrm{CHD}$. Hence, salvianolic acid A, salvianolic acid B, protocatechuic aldehyde were chosen as the representative component of water-soluble compounds, and tanshinone I, tanshinone IIA, cryptotanshinone, dihydrotanshinone I were chosen as the representative compound of liposoluble compounds to study the mechanism of Danshen in treating coronary heart disease.

The target's information of active components was obtained based on pharmacophore virtual screening and the component-protein interaction database including ChEMBL (https://www.ebi.ac.uk/chembl/\#) and STITCH4.0 (http://stitch.embl.de/). The pharmacophore virtual screening is a method to search for pharmacophore that matches the active compounds based on the 100 pharmacophore models associated with blood circulation. The target, whose Fit value score with active components of Danshen above 0.7 was selected as the target of active components of Danshen. ChEMBL [25] is an Open Data database that allows users to search for components and targets, containing 5.4 million bioactivity measurements for more than 1 million compounds and 5200 protein targets. STITCH [26] is a database of protein-chemical interactions in which every interaction has a confidence score, and the confidence score above 0.7 was selected.

\section{Network construction}

The protein-protein interaction information was extracted from the online updated databases of STRING 10(http://string-db.org). STRING [27] is a database of known and predicted protein-protein interactions, including direct (physical) and indirect (functional) associations. Every protein-protein interaction (PPI) has a confidence score, and confidence score above 0.7 were selected in order to ensure data reliability. The PPIs obtained from STRING 9.1 were imported into Cytoscape platform2.8.3, then the duplicated edges and self-loop edges were removed after union calculation using the Advanced Network Merge plug. The gene expression profile of CHD (No. GSE42148) was obtained from GEO (https://www.ncbi.nlm.nih.gov/geo/), including 13 disease samples. Then, the PPI network and CHD gene expression profile were integrated to construct the Ce-PIN.

\section{Network analysis}

In this study, FAG-EC algorithm was used to cluster the co-expression networks under disease state. FAG-EC [28] algorithm is a fast hierarchical agglomerative algorithm based on edge clustering coefficients, which can deal with large complex networks due to the low computational complexity. The Complex Size Threshold is set to 4 to identify module contained at least four nodes. Based on the identified modules, GO enrichment analysis was used to predict possible biological roles of the modules by evaluating the involved biological processes, using the BinGO [29] plugin for Cytoscape platform whose significant selection was set to 0.05 . Gene Ontology information and annotation information are from Gene ontology [30] (http://geneontology.org/). 


\section{Results}

Data mining

The phenolic acids received a total of 42 targets (Additional file 1: Table S1). The tanshinones received a total of 101 targets. (Additional file 2: Table S2).

\section{Network construction}

The Ce-PIN of phenolic acids has 324 nodes and 399 edges; The Ce-PIN of tanshinones has 612 nodes and 891 edges. However, the constructed network was not fully connected due to the unclear human protein interactions at present, thus the largest subgraph network was selected to carry out subsequently by removing the duplicated edges and self-loop edges. The subnetwork of phenolic acids has 244 nodes and 338 edges (Fig. 1); the subnetwork of tanshinones has 520 nodes and 819 edges (Fig. 2).

\section{Discussion}

\section{The Ce-PIN of phenolic acids}

With the FAG-EC algorithm, 21 modules were identified (Fig. 3). All 21 modules included 244 of the total 324 proteins. Based on the identified modules, GO enrichment analysis was used to predict possible biological roles of the modules using the BinGO plugin for Cytoscape platform. For each module, the most significant GO biological processes were chosen to evaluate the mechanism of modules. The results have been shown in Table 1.

The regulation of blood coagulation (Module 2、 Module11、Module18) contained proteins such as proteinaseactivated receptor 1 (F2R), thromboxane A2 receptor (TBXA2R), coagulation factor IX(F9), coagulation factor $\mathrm{X}(\mathrm{F} 10)$, coagulation factor $\mathrm{V}(\mathrm{F} 5)$, antithrombin-III (SERPINC1), heparin cofactor 2(SERPIND1), annexin A5(ANXA5). F2R is a member of the Proteinaseactivated receptor which play critical roles in atherosclerosis [31]. It has been recognized as a candidate to remedy the patients with acute coronary syndromes [32]. Thromboxane $\mathrm{A}_{2}\left(\mathrm{TXA}_{2}\right)$ is the arachidonate metabolite [33]. $\mathrm{TBXA}_{2} \mathrm{R}$ can interact specificity with $\mathrm{TXA}_{2}$ to induce platelet aggregation and constrict smooth muscle which belongs to the G-proteincoupled receptors superfamily [34]. A lot of $\mathrm{TXA}_{2}$ receptor antagonists have been developed as therapeutic antagonist for thrombosis, hypertension and asthma [35]. F9 is a vitamin K-dependent plasma protein involved in the intrinsic pathway of the coagulation cascade [36]. F9 inhibitors can attenuate clot formation as safe and effective anticoagulants [37]. F10 is a vitamin K-dependent plasma glycoprotein which is involved in the activation of thrombin by intrinsic and extrinsic pathway of Coagulation cascades [38]. F5 is essential cofactor in the prothrombinase complex and results in generation of thrombin [39, 40]. SERPINC1 can inhibit factor Xa and thrombin as a potent inhibitor of blood coagulation [41]. SERPIND1 is a plasma glycoprotein that inhibit thrombin specifically, which is activated by heparin or dermatan sulfate $[42,43]$. ANXA5 is a member of the annexin proteins as anticoagulant and antithrombotic protein [44]. It has been demonstrated to inhibit production of thrombin and activation of factor $\mathrm{X}$ [45]. Previous study had demonstrated that Salvianolic acid A inhibited human platelet aggregation induced by ADP in vitro or vivo [15]. These indicate that watersoluble compounds extracted form Danshen may regulate blood coagulation in coronary atherosclerotic heart disease by F2R, TBXA2R, F9, F10, F5, SERPINC1, SERPIND1 and ANXA5.

The regulation of blood circulation (module 9) contained proteins such as extracellular calcium-sensing receptor (CASR), endothelin-1 receptor (EDNRA), endothelin b receptor (EDNRB), kininogen-1 (KNG1). CASR is a G protein-coupled transmembrane receptor [46], which maintain and regulate systemic calcium homeostasis by inhibits secretion of parathyroid hormone in parathyroid glands [47]. Previous study has suggested that CASR contracted vessel by mediating regulation of contraction in vascular smooth muscle cells [48]. The endothlin-1(ET-1) is a member of the endothelin family of peptides (ET-1, ET-2, ET-3), which can be mediated by $\mathrm{ET}_{\mathrm{A}}$ and $\mathrm{ET}_{\mathrm{B}}$ receptor. The $\mathrm{ET}_{\mathrm{B}}$ receptor is non-specific receptor for ET-1, ET-2, ET-3, whereas $\mathrm{Th}_{\mathrm{AT}} \mathrm{ET}_{\mathrm{A}}$ receptor has a higher affinity for ET-1 [49]. Binding of ET to ET receptors on the endothelium induce the production of $\mathrm{NO}$ and prostacyclin, which result in vasodilation [50]. KNG1 is cleaved by plasma prekallikrein in the kallikrein-kinin system, releasing bradykinin, a most potent vasodilator, resulting in the vasodilation $[51,52]$. It is reported that Salvianolic acid B exerts vasodilation activity through $\mathrm{NO}$ related signals [53]. To sum up, water-soluble compounds of Danshen may play a role in blood circulation by CASR, EDNRA, EDNRB, KNG1, to treat the coronary heart disease.

The regulation of lipid metabolism (module 20, 21) contained proteins such as insulin (INS), peroxisome proliferator-activated receptor alpha (PPARA). INS promotes the synthesis of lipids, and inhibits their degradation, which is correlated with the increase of transcription factor steroid regulatory element-binding protein (SREBP)-1c [54]. Insulin resistance is a pathogenetic factor in the development of atherosclerosis in diabetes [55]. Recent studies have demonstrated that impaired insulin signaling accelerates atherosclerosis [56]. PPARA is a ligand-activated transcription factor, which expression by macrophages has antiatherogenic effects by modulation of cell cholesterol trafficking and inflammatory activity [57]. It is reported that salvianolic acids are the major effective components of DanQi pill in improving lipid metabolism in ischemic heart 


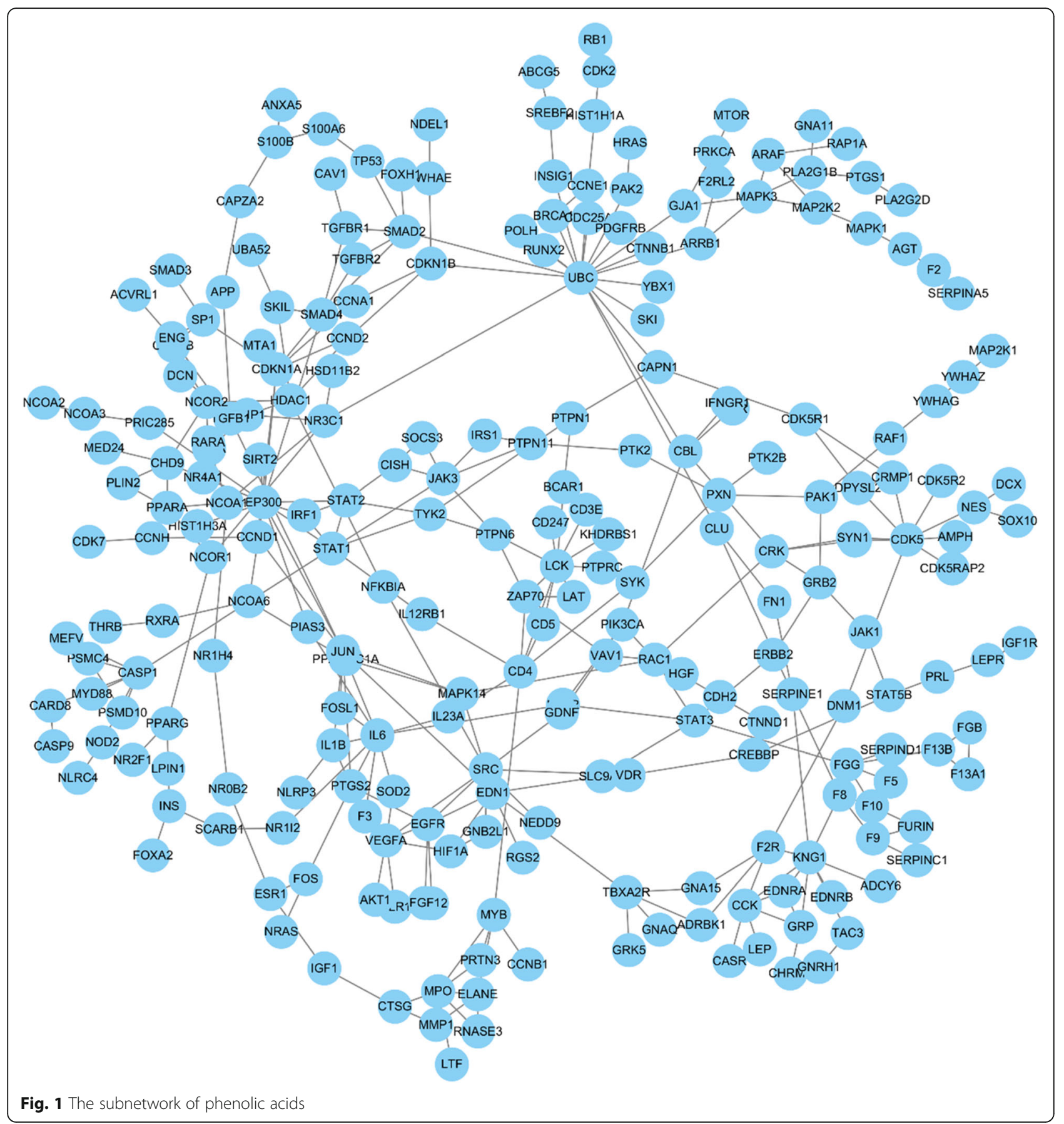

model, which may be mediated by regulating transcriptional factors such as PPARs, RXRA and PGC-1 alpha [58]. These indicate that water-soluble compounds extracted form Danshen may regulate lipid metabolism in coronary atherosclerotic heart disease by INS, PPARA.

The regulation of immune response (module 6, 16) contained proteins such as $\mathrm{T}$-cell surface glycoprotein CD4(CD4), receptor-type tyrosine-protein phosphatase C(PTPRC), T-cell surface glycoprotein CD5(CD5), tyrosine-protein kinase lck (LCK), linker for activation of T-cells family member 1 (LAT), caspase-1(CASP1). CD4 is cell surface glycoproteins expressed on T lymphocytes that play a major role in both the activation of mature peripheral $\mathrm{T}$ cells and the thymic differentiation process [59]. The down-regulation of CD5 may reduce the dysregulation proliferation of $\mathrm{CD}^{+} \mathrm{T}$-cells. It has been reported that the water-soluble phenolic compound of Danshen were able to increase $\mathrm{CD} 4 \mathrm{~T}$ cell to treat 


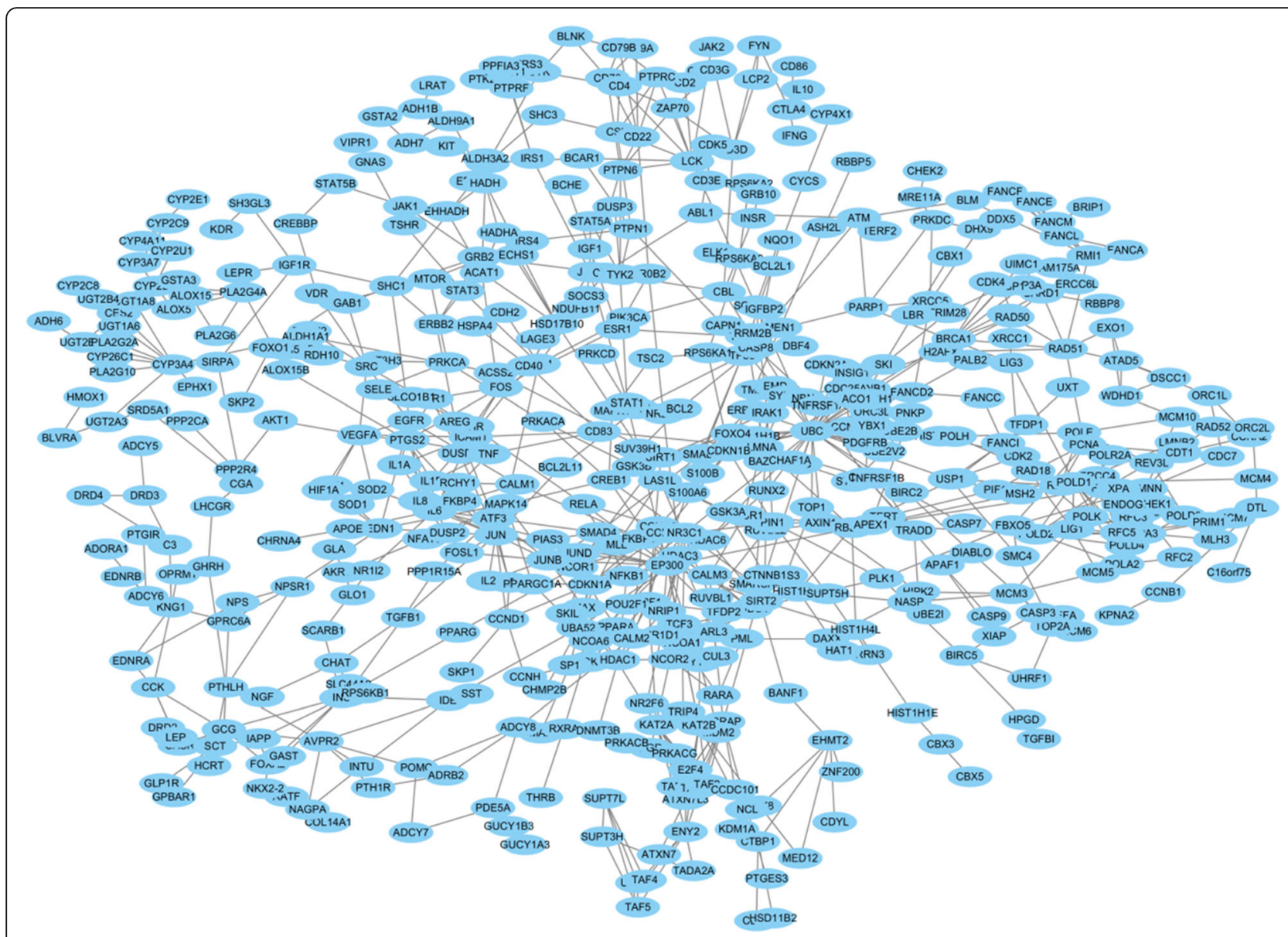

Fig. 2 The subnetwork of tanshinones

atherosclerosis by modulating the inflammation [60]. PTPRC is a member of protein tyrosine phosphatase (PTP) family that plays important role in immune response [61]. The LCK in the inactive state is modulated by RhoH contributing to the regulation of both ore-TCR and TCR signaling during T-cell development [62]. The LAT is a palmitoylated integral membrane adaptor protein that is phosphorylated by protein tyrosine kinases (PTK) and binds to the adaptors Gads, Grb2 and phospholipase $\mathrm{C} \gamma 1$ (PLC $\gamma 1$ ) to drive $\mathrm{T}$-cell activation [63]. The CASP1 is a cysteine protease that acts as an essential regulator of inflammatory responses [64]. Innate immunity plays a role in both thrombosis and inflammation [65]. Recent research has reported that mast cells are participated in atherosclerosis by releasing proinflammatory molecules and vasoactive mediators [66]. It is reported that Salvianolic acid A blocked inflammatory responses by impairing NF-kappa B signaling [67]. These indicate that water-soluble compounds extracted form Danshen may regulate immune response/inflammation in coronary atherosclerotic heart disease by CD4, CD5, PTPRC, LCK, LAT, CASP1.

\section{The Ce-PIN of tanshinones}

With the FAG-EC algorithm, 39 modules were identified (Fig. 4). All 21 modules included 520 of the total 612 proteins. Based on the identified modules, GO enrichment analysis was used to predict possible biological roles of the modules using the BinGO plugin for Cytoscape platform. For each module, the most significant GO biological processes were chosen to evaluate the mechanism of modules. The results have been shown in Table 2.

The regulation of blood circulation/coagulation (module 28) contained proteins such as guanylate cyclase soluble subunit alpha-3(GUCY1A3), guanylate cyclase soluble subunit beta-1(GUCY1B3). GUCY1A3 and GUCY1B3 encodes for the $\alpha 1$ subunit and $\beta 1$ subunit of soluble guanylate cyclase (SGC), respectively. GUCY1A3 mutations increases risk for moyamoya disease, achalasia and hypertension [68]. The SGC is the central enzyme in the NO-cGMP signalling pathway to protect the heart from ischemia and reperfusion injury, which has been used in treatment of coronary heart disease for 100 years [69]. It is reported that Tanshinone IIA protects against 

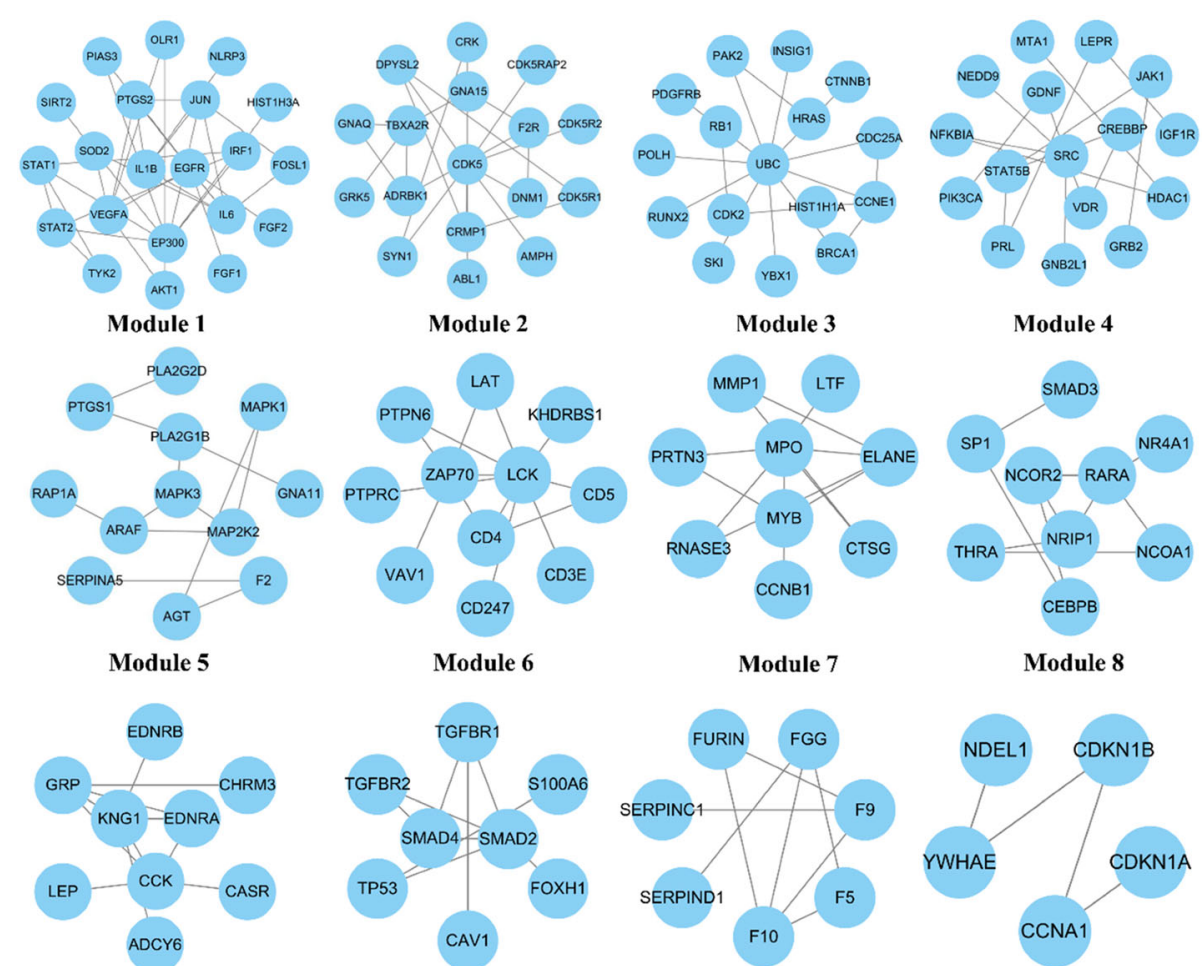

Module 7

Module 8
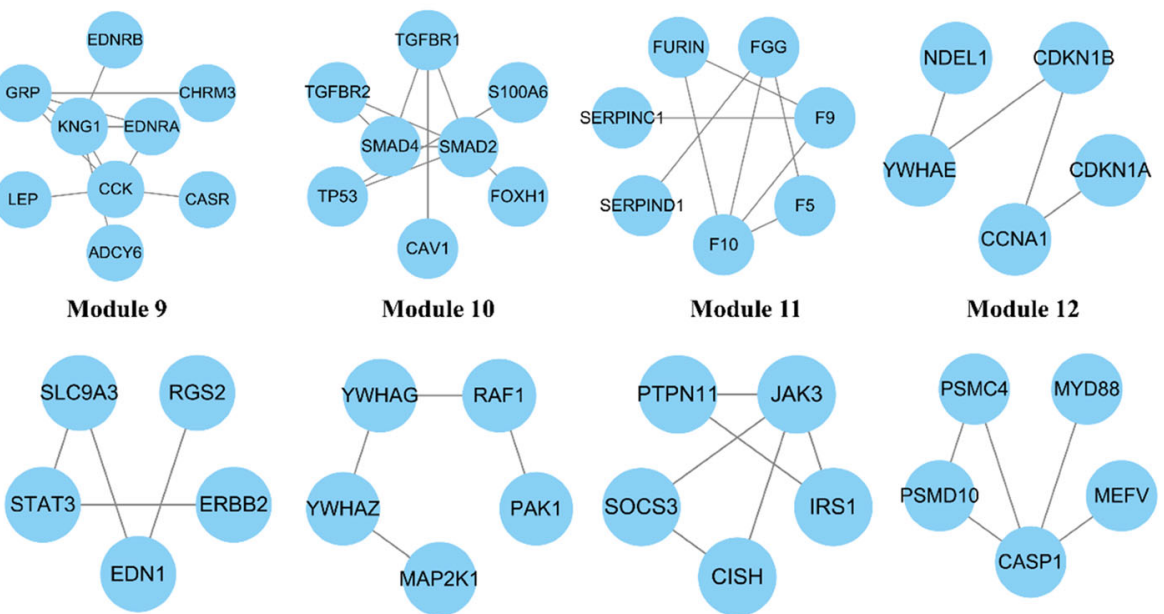

Module 10

Module 11

Module 12
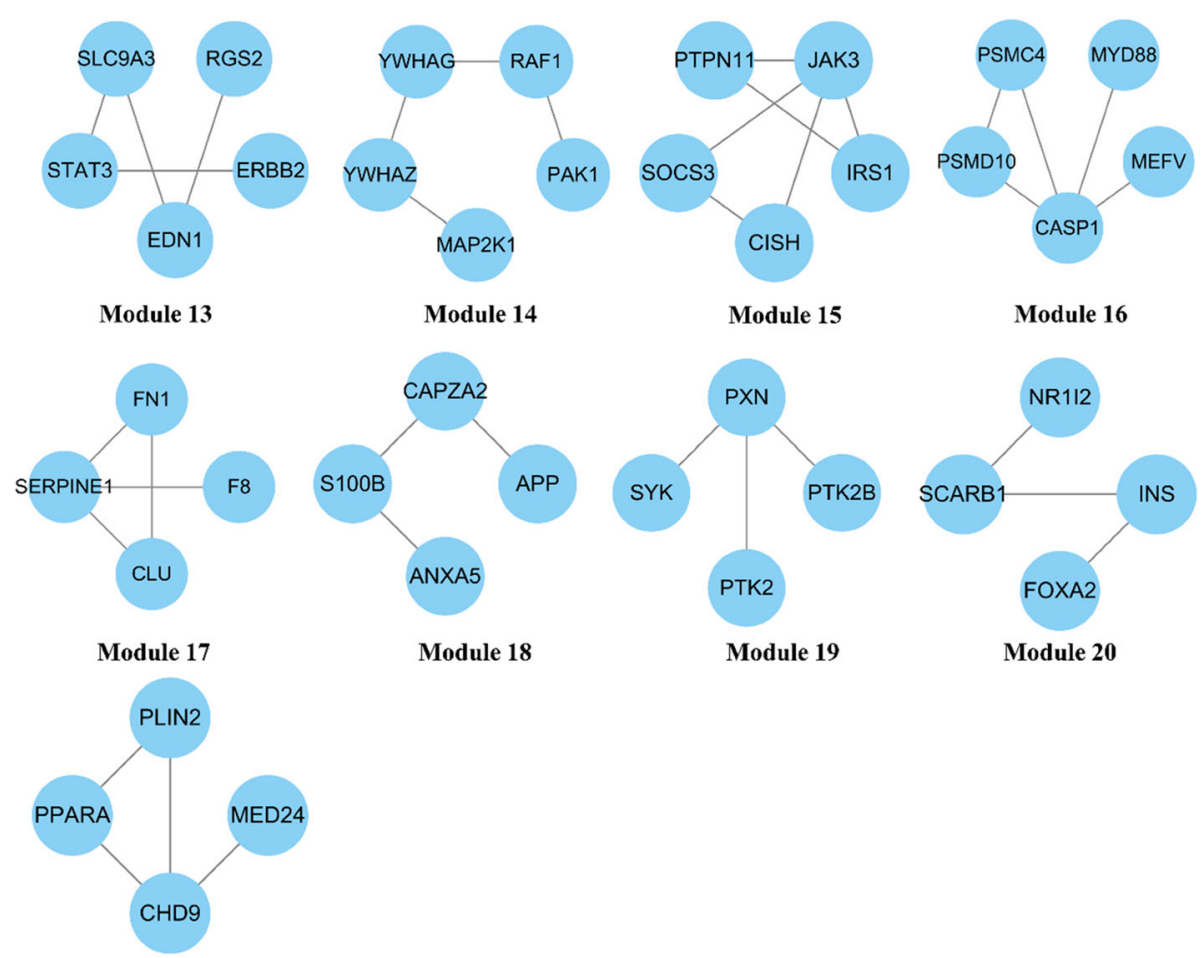

Module 18

Module 19

Module 20

Module 21

Fig. 3 Modules in the Ce-PIN of phenolic acids 
Table $1 \mathrm{GO}$ biological process terms of phenolic acids modules display partially

\begin{tabular}{|c|c|c|}
\hline Modules & GO terms & $P$-value \\
\hline Module1 & response to chemical & $1.48 \times 10^{-15}$ \\
\hline \multirow[t]{2}{*}{ Module2 } & blood coagulation & $8.33 \times 10^{-9}$ \\
\hline & coagulation & $8.33 \times 10^{-9}$ \\
\hline Module3 & positive regulation of nucleobase-containing compound metabolic process & $6.92 \times 10^{-11}$ \\
\hline Module4 & enzyme linked receptor protein signaling pathway & $3.49 \times 10^{-10}$ \\
\hline Module5 & positive regulation of protein phosphorylation & $7.36 \times 10^{-11}$ \\
\hline \multirow[t]{2}{*}{ Module6 } & regulation of $\mathrm{T}$ cell activation & $4.49 \times 10^{-19}$ \\
\hline & positive regulation of $\mathrm{T}$ cell activation & $6.19 \times 10^{-18}$ \\
\hline Module7 & extracellular matrix disassembly & $7.25 \times 10^{-8}$ \\
\hline Module8 & transcription initiation from RNA polymerase II promoter & $8.57 \times 10^{-12}$ \\
\hline \multirow[t]{2}{*}{ Module9 } & blood circulation & $2.17 \times 10^{-8}$ \\
\hline & vasodilation & $2.04 \times 10^{-7}$ \\
\hline Module10 & transforming growth factor beta receptor signaling pathway & $5.35 \times 10^{-13}$ \\
\hline \multirow[t]{2}{*}{ Module11 } & blood coagulation & $1.87 \times 10^{-10}$ \\
\hline & coagulation & $1.87 \times 10^{-10}$ \\
\hline Module12 & mitotic cell cycle & $9.46 \times 10^{-9}$ \\
\hline Module13 & regulation of cardiac muscle hypertrophy & $4.10 \times 10^{-6}$ \\
\hline Module14 & regulation of protein kinase activity & $2.65 \times 10^{-6}$ \\
\hline Module15 & JAK-STAT cascade involved in growth hormone signaling pathway & $2.09 \times 10^{-12}$ \\
\hline Module16 & immune system process & $5.75 \times 10^{-6}$ \\
\hline Module17 & positive regulation of molecular function & $2.01 \times 10^{-7}$ \\
\hline \multirow[t]{2}{*}{ Module18 } & blood coagulation & $2.13 \times 10^{-5}$ \\
\hline & coagulation & $2.13 \times 10^{-5}$ \\
\hline Module19 & signal complex assembly & $4.78 \times 10^{-11}$ \\
\hline Module20 & positive regulation of lipid biosynthetic process & $2.21 \times 10^{-5}$ \\
\hline \multirow[t]{2}{*}{ Module21 } & fatty acid transport & $2.06 \times 10^{-5}$ \\
\hline & cellular lipid metabolic process & $2.92 \times 10^{-4}$ \\
\hline
\end{tabular}

myocardial ischemia reperfusion injury by activating the PI3K/Akt/mTOR signaling pathway [70]. Hence, tanshinones may regulate the blood circulation by GUCY1A3 and GUCY1B3 to protects against myocardial ischemia reperfusion injury.

The regulation of lipid metabolism (module 20, 21) contained proteins such as group 10 secretory phospholipase A2(PLA2G10), cytochrome P450 3A4(CYP3A4). PLA2G10 belongs to the phospholipase A2 family, which plays a important role in atherogenesis [71]. The fatty acid can be hydrolyse specifically by the A2 group of phospholipases (PLA2s) at the sn-2, or second carbon positions on the glycerol backbone of the phospholipids, and release fatty acid and lysophospholipid [72]. The animal and human studies suggest that high levels of secretory phospholipase A2(sPLA2) may be implicated in the initial and later stages of the development of the atherosclerotic plaque [73, 74]. Cytochrome P450 3A4 is a member of the cytochrome $\mathrm{P} 450(\mathrm{CYP})$ family. It is reported that CYP-mediated eicosanoid metabolism is dysregulated in certain subsets of CHD patients, and demonstrate that biomarkers of CYP epoxygenase and soluble epoxide hydrolase, but not CYP-hydroxylase, metabolism are altered in stable CHD patients relative to healthy individuals [75]. The study indicated that Tanshinone IIA was able to regulate lipid metabolism by miR-33a/SREBP-2/Pcsk9 signaling pathway to reduce lipid deposition in the liver of hyperlipidemia rat [76].

The regulation of immune responsec(module $8,22,33$ ) contained proteins such as $\mathrm{T}$-cell surface glycoprotein CD4(CD4), receptor-type tyrosine-protein phosphatase C(PTPRC), tyrosine-protein kinase Fyn(FYN), T-cell surface glycoprotein CD3 epsilon chain(CD3E), T-cell surface glycoprotein CD3 gamma chain(CD3G), T-cell surface glycoprotein CD3 delta chain(CD3D), B-cell antigen receptor complex-associated protein beta chain(CD79B), $\mathrm{B}$-cell antigen receptor complex-associated protein alpha chain(CD79A). CD4 is cell surface glycoproteins expressed 


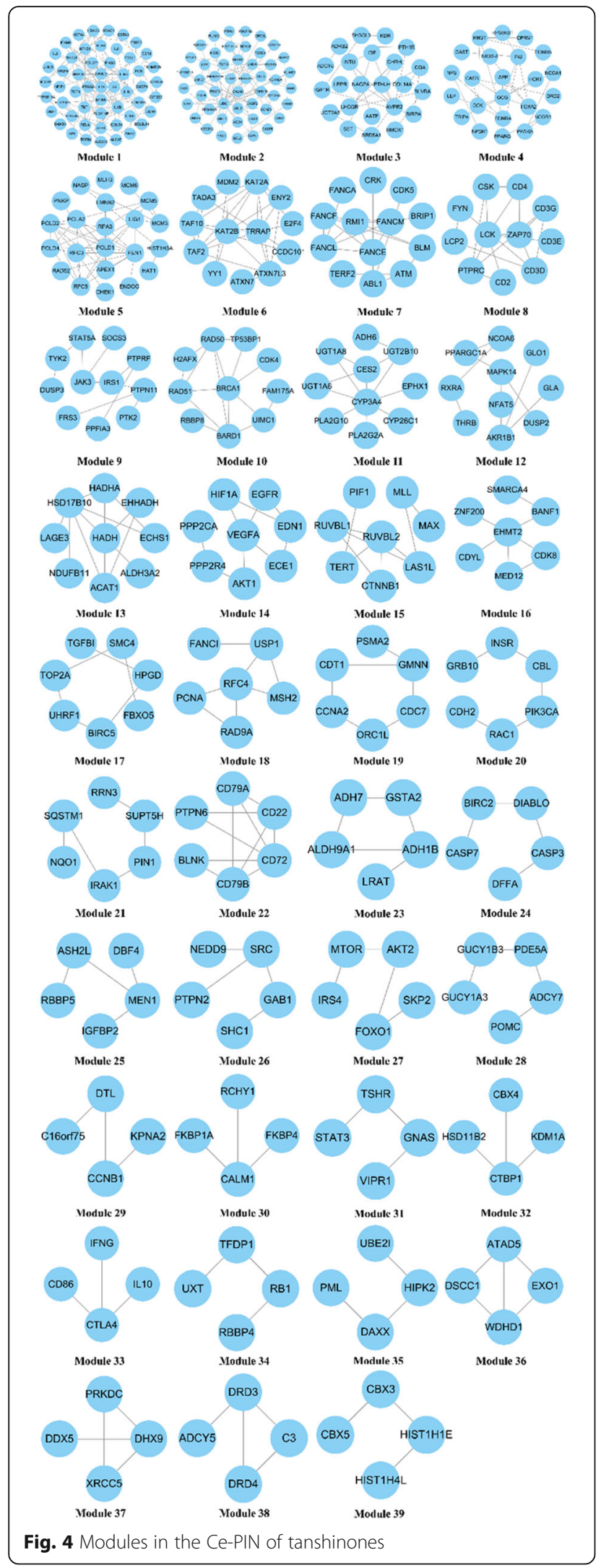

on $\mathrm{T}$ lymphocytes that play a major role in both the activation of mature peripheral $\mathrm{T}$ cells and the thymic differentiation process [77]. PTPRC is a member of protein tyrosine phosphatase (PTP) family that plays a important role in immune response [60]. The LCK and FYN are two members of the Src family of tyrosine kinases which play important role in the $\alpha \beta$ TCR-coupled signaling pathway. The expression level's change of Lck and Fyn induce T cell development and maturation [78]. The CD3E, CD3G, CD3D are the components of TCR/CD3 complex which are expressed on the cell surface to mediates signal transduction $[79,80]$. The CD79A and CD70B are transmembrane glycoproteins belonging to the Ig superfamily. They play an immunomodulatory role by mediating surface expression and signaling of diverse $\mathrm{B}$ cell receptor complexes on precursor, immature, and mature B cells [81]. Innate immunity plays a role in both thrombosis and inflammation [64]. Dendritic cells (DC), the potent antigen-presenting cells, stimulate T-cell proliferation and activation to induce the growth of atherosclerotic plaques during adaptive immunity [82]. Tanshinone IIA had been shown to inhibit DC maturation and decreases the expression of proinflammatory cytokines to decrease the growth of atherosclerotic lesions [83]. These indicate that liposoluble compounds extracted form Danshen may regulate immune response/inflammation in coronary atherosclerotic heart disease by CD4, PTPRC, FYN, CD3E, CD3G, CD3D, CD79B, CD79A.

\section{The synergetic effects of Danshen}

According to the analysis of FAG-EC algorithm and GO enrichment, Danshen may play the role in the treatment of CHD by regulating the blood circulation, immune response and lipid metabolism. However, phenolic acids may regulate the blood circulation by CASR, EDNRA, EDNRB, KNG1, tanshinones regulated the blood circulation by GUCY1A3 and GUCY1B3 (Fig. 5). It is suggested that two compounds of Danshen may regulate the same metabolic process via the different module mediated by different proteins. In addition, both the phenolic acids and tanshinones may regulate the immune response or inflammation by CD4, PTPRC. It is suggested that two compounds of Danshen may regulate the same metabolic process via the different module mediated by the same proteins. This indicated that the synergy of phenolic acids and tanshinones was able to be illustrated based on the functional modules.

\section{Conclusions}

In this study, the Ce-PIN of phenolic acids and tanshinones were established to elaborate the mechanism of treatment of CHD based on module-based network analysis approach. The phenolic acids may be partly attributed to the regulation of blood coagulation/circulation 
Table 2 GO biological process terms of tanshinones modules display partially

\begin{tabular}{|c|c|c|}
\hline Modules & GO terms & $P$-value \\
\hline Module 1 & response to chemical stimulus & $1.64 \times 10^{-25}$ \\
\hline Module 2 & regulation of cellular protein metabolic process & $5.07 \times 10^{-15}$ \\
\hline Module 3 & G-protein coupled receptor signaling pathway, coupled to cyclic nucleotide second messenger & $3.86 \times 10^{-11}$ \\
\hline Module 4 & positive regulation of cellular process & $1.23 \times 10^{-14}$ \\
\hline Module 5 & DNA strand elongation involved in DNA replication & $9.21 \times 10^{-31}$ \\
\hline Module 6 & histone deubiquitination & $1.25 \times 10^{-17}$ \\
\hline Module 7 & DNA metabolic process & $3.76 \times 10^{-13}$ \\
\hline \multirow[t]{2}{*}{ Module 8} & T cell receptor signaling pathway & $4.80 \times 10^{-24}$ \\
\hline & regulation of $\mathrm{T}$ cell activation & $4.77 \times 10^{-19}$ \\
\hline Module 9 & growth hormone receptor signaling pathway & $1.65 \times 10^{-13}$ \\
\hline Module 10 & double-strand break repair & $7.40 \times 10^{-18}$ \\
\hline Module 11 & lipid metabolic process & $6.71 \times 10^{-6}$ \\
\hline Module 12 & transcription from RNA polymerase II promoter & $2.63 \times 10^{-7}$ \\
\hline Module 13 & lipid oxidation & $6.42 \times 10^{-9}$ \\
\hline Module 14 & positive regulation of catalytic activity & $7.76 \times 10^{-10}$ \\
\hline Module 15 & histone acetylation & $1.91 \times 10^{-6}$ \\
\hline Module 16 & nucleic acid metabolic process & $4.33 \times 10^{-6}$ \\
\hline Module 17 & cell division & $2.83 \times 10^{-6}$ \\
\hline Module 18 & DNA repair & $2.79 \times 10^{-10}$ \\
\hline Module 19 & M/G1 transition of mitotic cell cycle & $6.21 \times 10^{-13}$ \\
\hline Module 20 & enzyme linked receptor protein signaling pathway & $2.07 \times 10^{-7}$ \\
\hline Module 21 & positive regulation of cellular process & $1.46 \times 10^{-5}$ \\
\hline \multirow[t]{2}{*}{ Module 22} & positive regulation of immune response & $1.37 \times 10^{-4}$ \\
\hline & activation of immune response & $7.48 \times 10^{-5}$ \\
\hline Module 23 & ethanol oxidation & $1.19 \times 10^{-6}$ \\
\hline Module 24 & cellular component disassembly involved in execution phase of apoptosis & $2.33 \times 10^{-10}$ \\
\hline Module 25 & histone lysine methylation & $3.01 \times 10^{-8}$ \\
\hline Module 26 & enzyme linked receptor protein signaling pathway & $5.33 \times 10^{-6}$ \\
\hline Module 27 & regulation of fatty acid beta-oxidation & $3.30 \times 10^{-6}$ \\
\hline \multirow[t]{2}{*}{ Module 28} & blood circulation & $1.38 \times 10^{-5}$ \\
\hline & blood coagulation & $5.26 \times 10^{-5}$ \\
\hline Module 29 & regulation of chromosome condensation & $1.31 \times 10^{-4}$ \\
\hline Module 30 & regulation of lipoprotein lipase activity & $8.15 \times 10^{-6}$ \\
\hline Module 31 & G-protein coupled receptor signaling pathway, coupled to cyclic nucleotide second messenger & $6.95 \times 10^{-7}$ \\
\hline Module 32 & negative regulation of histone modification & $6.83 \times 10^{-6}$ \\
\hline \multirow[t]{2}{*}{ Module 33} & regulation of T cell activation & $1.93 \times 10^{-8}$ \\
\hline & regulation of immune response & $7.63 \times 10^{-7}$ \\
\hline Module 34 & G1 phase of mitotic cell cycle & $1.06 \times 10^{-5}$ \\
\hline Module 35 & virus-host interaction & $4.31 \times 10^{-8}$ \\
\hline Module 36 & heterochromatin maintenance & $1.31 \times 10^{-4}$ \\
\hline Module 37 & double-strand break repair via nonhomologous end joining & $2.99 \times 10^{-6}$ \\
\hline Module 38 & G-protein coupled receptor signaling pathway & $3.78 \times 10^{-7}$ \\
\hline Module 39 & chromatin organization & $4.23 \times 10^{-5}$ \\
\hline
\end{tabular}




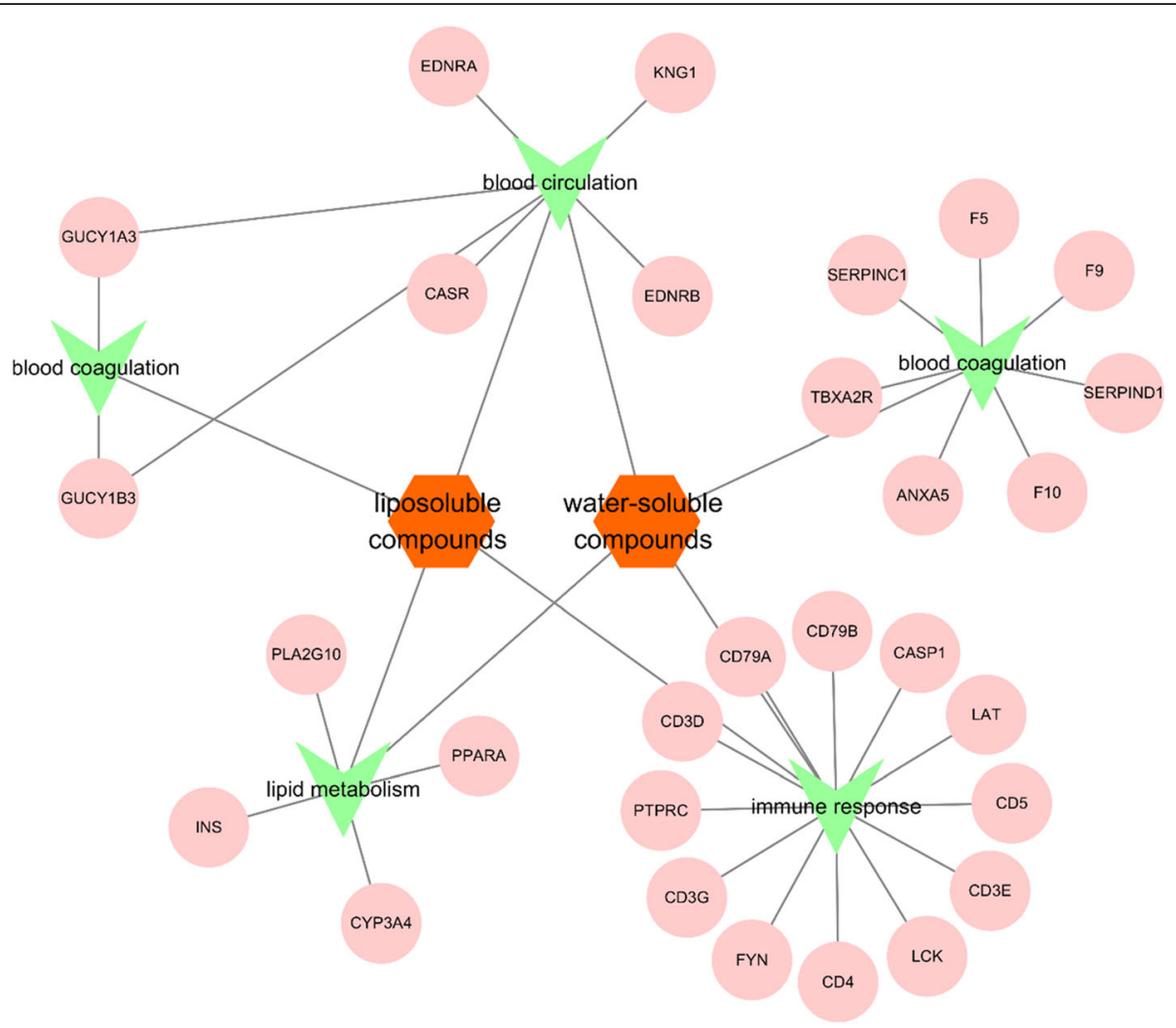

Fig. 5 The Synergetic Effects of Danshen

process, immune/inflammation process, lipid metabolic process to treat $\mathrm{CHD}$, while the tanshinones may treat CHD through the regulation of blood circulation process, immune/inflammation process, lipid metabolic process. The two compounds of Danshen may regulate the same metabolic pathway through different modules, which reflect the synergistic effect between Chinese medicine components at the molecular level. It would be helpful for guiding the research and development of the novel drugs of Danshen. Further experiments are needed to confirm the conclusions. This study provides a novel approach to understand the mechanisms of Danshen of treatment in CHD. What's more, the scientific intension of "synergy" of TCM may be also illustrated based on the functional modules at the molecular level.

\section{Supplementary information}

Supplementary information accompanies this paper at https://doi.org/10. 1186/s12906-019-2712-4

Additional file 1: Table S1. The targets' information of phenolic acids. Additional file 2: Table S2. The targets' information of tanshinones.

\section{Abbreviations}

ANXA5: Annexin A5; CASP1: Caspase-1; CASR: Extracellular calcium-sensing receptor; CD3D: T-cell surface glycoprotein CD3 delta chain; CD3E: T-cell surface glycoprotein CD3 epsilon chain; CD3G: T-cell surface glycoprotein
CD3 gamma chain; CD4: T-cell surface glycoprotein CD4; CD5: T-cell surface glycoprotein CD5; CD79A: B-cell antigen receptor complex-associated protein alpha chain; CD79B: B-cell antigen receptor complex-associated protein beta chain; Ce-PIN: Co-expression protein interaction networks;

CYP3A4: Cytochrome P450 3A4; EDNRA: Endothelin-1 receptor;

EDNRB: Endothelin b receptor; F10: Coagulation factor X; F2R: Proteinaseactivated receptor 1; F5: Coagulation factor V; F9: Coagulation factor IX;

FYN: Tyrosine-protein kinase Fyn; GUCY1A3: Guanylate cyclase soluble subunit alpha-3; GUCY1B3: Guanylate cyclase soluble subunit beta-1; INS: insulin; KNG1: Kininogen-1; LAT: Linker for activation of T-cells family member 1; LCK: Tyrosine-protein kinase Ick; PIN: Protein interaction network; PLA2G10: Group 10 secretory phospholipase A2; PPARA: Peroxisome proliferator-activated receptor alpha; PPI: Protein-protein interaction; PTPRC: Receptor-type tyrosine-protein phosphatase C;

SERPINC1: Antithrombin-III; SERPIND1: Heparin cofactor 2;

TBXA2R: Thromboxane A2 receptor; TCM: Traditional Chinese medicine

\section{Acknowledgements}

Not applicable.

Authors' contributions

$Y Q, Y Z$ and DW designed the research; DW and $M H$ analyzed. and interpreted the data; DW drafted the manuscript; $\mathrm{MH}$ and XC. revised the manuscript. All authors read and approved the final manuscript.

\section{Funding}

This research was supported by National Natural Science Foundation of China (No. 81430094, No. 81573831). The funding bodies had no involvement in the concept, design, analysis or writing the manuscript.

Availability of data and materials

The datasets generated and analyzed during the study are available from the corresponding author on reasonable request. 


\section{Ethics approval and consent to participate}

Not applicable.

\section{Consent for publication}

Not applicable.

\section{Competing interests}

The authors declare that they have no competing interests.

Received: 10 March 2019 Accepted: 10 October 2019

Published online: 03 February 2020

\section{References}

1. Lopez AD, Mathers CD, Ezzati M, Jamison DT, Murray CJL. Global and regional burden of disease and risk factors, 2001: systematic analysis of population health data. Lancet. 2006;367(9524):1747-57.

2. Wang F, Xu CQ, He Q, Cai JP, Li XC, Wang D, Xiong X, Liao YH, Zeng QT, Yang YZ, et al. Genome-wide association identifies a susceptibility locus for coronary artery disease in the Chinese Han population. Nat Genet. 2011; 43(4):345-U396.

3. Ramakrishnan AVKP, Varghese TP, Vanapalli S, Nair NK, Mingate MD. Platelet activating factor: a potential biomarker in acute coronary syndrome? Cardiovasc Ther. 2017;35(1):64-70.

4. Libby P. Inflammation and cardiovascular disease mechanisms. Am J Clin Nutr. 2006;83(2):456s-60s.

5. Stanton T, Dunn FG. Hypertension, left ventricular hypertrophy, and myocardial ischemia. Med Clin N Am. 2017;101(1):29-41.

6. Yang $X Y$, He TM, Han SJ, Zhang XY, Sun Y, Xing YW, Shang HC. The Role of Traditional Chinese Medicine in the Regulation of Oxidative Stress in Treating Coronary Heart Disease. Oxid Med Cell Longev. 2019;24.

7. Wang Y, Lin WL, Li C, Singhal S, Jain G, Zhu LX, Lu LH, Zhu RX, Wang W. Multipronged therapeutic effects of Chinese herbal medicine Qishenyiqi in the treatment of acute myocardial infarction. Front Pharmacol. 2017;8.

8. Cheng TO. Cardiovascular effects of Danshen. Int J Cardiol. 2007;121(1):9-22.

9. Zhang JL, He Y, Cui M, Li L, Yu HL, Zhang GF, Guo D. Metabolic studies on the total phenolic acids from the roots of Salivia miltiorrhiza in rats. Biomed Chromatogr. 2005;19(1):51-9.

10. Han JY, Fan JY, Horie Y, Miura S, Cui DH, Ishii H, Hibi T, Tsuneki H, Kimura I. Ameliorating effects of compounds derived from Salvia miltiorrhiza root extract on microcirculatory disturbance and target organ injury by ischemia and reperfusion. Pharmacol Therapeut. 2008;117(2):280-95.

11. Hu P, Liang QL, Luo GA, Zhao ZZ, Jiang ZH. Multi-component HPLC fingerprinting of radix salviae miltiorrhizae and its LC-MS-MS identification. Chem Pharm Bull. 2005:53(6):677-83.

12. Ho JHC, Hong CY. Salvianolic acids: small compounds with multiple mechanisms for cardiovascular protection. J Biomed Sci. 2011;18.

13. Luo HL, Kong WJ, Hu YC, Chen P, Wu XR, Wan L, Yang MH. Quality evaluation of Salvia miltiorrhiza Bge. By ultra high performance liquid chromatography with photodiode array detection and chemical fingerprinting coupled with chemometric analysis. J Sep Sci. 2015;38(9): 1544-51.

14. Sun YS, Zhu HF, Wang JH, Liu ZB, Bi JJ. Isolation and purification of salvianolic acid a and salvianolic acid B from Salvia miltiorrhiza by highspeed counter-current chromatography and comparison of their antioxidant activity. J Chromatogr B. 2009;877(8-9):733-7.

15. Fan HY, Fu FH, Yang MY, Xu H, Zhang AH, Liu K. Antiplatelet and antithrombotic activities of salvianolic acid a. Thromb Res. 2010;126(1):E17-22.

16. Lee JC, Park JH, Park OK, Kim IH, Yan BC, Ahn JH, Kwon SH, Choi JH, Kim JD, Won MH. Neuroprotective effects of tanshinone I from Danshen extract in a mouse model of hypoxia-ischemia. Anat Cell Biol. 2013;46(3):183-90.

17. Wang DD, Zhang WX, Wang TT, Li N, Mu HB, Zhang JW, Duan JY. Unveiling the mode of action of two antibacterial Tanshinone derivatives. Int J Mol Sci. 2015;16(8):17668-81.

18. Zhao JL, Lou JF, Mou Y, Li PQ, Wu JY, Zhou LG. Diterpenoid Tanshinones and phenolic acids from cultured hairy roots of Salvia miltiorrhiza Bunge and their antimicrobial activities. Mol. 2011;16(3):2259-67.

19. Wu ZK, Zhao XM, Chen LN. Identifying responsive functional modules from protein-protein interaction network. Mol Cells. 2009;27(3):271-7.

20. Ren W, Gao S, Zhang H, Ren Y, Yu X, Lin W, Guo S, Zhu R, Wang W. Decomposing the Mechanism of Qishen Granules in the Treatment of Heart Failure by a Quantitative Pathway Analysis Method. Mol. 2018;23(7):e1982.
21. Qiu JJ, Du ZG, Wang Y, Zhou YT, Zhang YX, Xie YY, Lv Q. Weighted gene co-expression network analysis reveals modules and hub genes associated with the development of breast cancer. Med. 2019;98(6):e14345.

22. Cline MS, Smoot M, Cerami E, Kuchinsky A, Landys N, Workman C, Christmas R, Avila-Campilo I, Creech M, Gross B, et al. Integration of biological networks and gene expression data using Cytoscape. Nat Protoc. 2007;2(10): 2366-82.

23. Taylor IW, Linding R, Warde-Farley D, Liu YM, Pesquita C, Faria D, Bull S, Pawson T, Morris Q, Wrana JL. Dynamic modularity in protein interaction networks predicts breast cancer outcome. Nat Biotechnol. 2009;27(2):199-204.

24. Cheng TMK, Gulati S, Agius R, Bates PA. Understanding cancer mechanisms through network dynamics. Brief Funct Genomics. 2012;1 1(6):543-60.

25. Gaulton A, Bellis LJ, Bento AP, Chambers J, Davies M, Hersey A, Light Y, McGlinchey S, Michalovich D, Al-Lazikani B, et al. ChEMBL: a large-scale bioactivity database for drug discovery. Nucleic Acids Res. 2012;40(D1): D1100-7.

26. Kuhn M, Szklarczyk D, Pletscher-Frankild S, Blicher TH, von Mering C, Jensen LJ, Bork P. STITCH 4: integration of protein-chemical interactions with user data. Nucleic Acids Res. 2014;42(D1):D401-7.

27. Szklarczyk D, Franceschini A, Wyder S, Forslund K, Heller D, Huerta-Cepas J, Simonovic M, Roth A, Santos A, Tsafou KP, et al. STRING v10: protein-protein interaction networks, integrated over the tree of life. Nucleic Acids Res. 2015;43(D1):D447-52.

28. Wang JX, Zhong JC, Chen G, Li M, Wu FX, Pan Y. ClusterViz: a Cytoscape APP for cluster analysis of biological network. leee Acm T Comput Bi. 2015; 12(4):815-22.

29. Maere S, Heymans K, Kuiper M. BiNGO: a Cytoscape plugin to assess overrepresentation of gene ontology categories in biological networks. Bioinformatics. 2005;21(16):3448-9.

30. Ashburner M, Ball CA, Blake JA, Botstein D, Butler H, Cherry JM, Davis AP, Dolinski K, Dwight SS, Eppig JT, et al. Gene ontology: tool for the unification of biology. Gene Ontology Consortium Nat Genet. 2000;25(1):25-9.

31. Ellertsdottir E, Berthold PR, Bouzaffour M, Dufourcq P, Trayer V, Gauron C, Vriz S, Affolter M, Rampon C. Developmental Role of Zebrafish Protease-Activated Receptor 1 (PAR1) in the Cardio-Vascular System. PLoS One. 2012;7(7):e42131.

32. Leger AJ, Covic L, Kuliopulos A. Protease-activated receptors in cardiovascular diseases. Circ. 2006;114(10):1070-7.

33. Matteo M, Cicinelli E, Sciorsci RL, Grandone E, Cardo G, Colaizzo D, Rizzo A, Greco P. Expression and hormonal modulation of the thromboxane A2 receptor gene in mammalian testicular arteries. Fertil Steril. 2006;85:1276-80.

34. Yang WL, Yan AJ, Zhang TT, Shao JX, Liu TY, Yang X, Xia WL, Fu Y. Thromboxane a(2) receptor stimulation enhances microglial Interleukin-1 beta and NO biosynthesis mediated by the activation of ERK pathway. Front Aging Neurosci. 2016;8.

35. Shen RF, Tai HH. Thromboxanes: synthase and receptors. J Biomed Sci. 1998:5(3):153-72.

36. Ding Y, Wang J, Tan W, Chen Y, Lu X, Lu Y, Li S, Li H, Wang L, Cheng J. Cloning, sequencing, and analysis of the full-length CDNA of rhesus monkey factor IX. Transpl P. 2008;40(8):2769-72.

37. Howard EL, Becker KCD, Rusconi CP, Becker RC. Factor IXa inhibitors as novel anticoagulants. Arterioscl Throm Vas. 2007;27(4):722-7.

38. Arasu A, Kumaresan V, Sathyamoorthi A, Arasu MV, Al-Dhabi NA, Arockiaraj J. Coagulation profile, gene expression and bioinformatics characterization of coagulation factor $X$ of striped murrel Channa striatus. Fish Shellfish Immun. 2016:55:149-58.

39. Tilley D, Levit I, Samis JA. Measurement of factor V activity in human plasma using a microplate coagulation assay. Jove-J Vis Exp. 2012;67.

40. Gale AJ, Bhat V, Pellequer JL, Griffin JH, Mosnier LO, Von Drygalski A. Safety, stability and pharmacokinetic properties of (super)factor $\mathrm{Va}$, a novel engineered coagulation factor $\mathrm{V}$ for treatment of severe bleeding. Pharm Res. 2016;33(6):1517-26.

41. Giardino EC, Haertlein BJ, de Garavilla L, Costanzo MJ, Damiano BP, Andrade-Gordon P, Maryanoff BE. Cooperative antithrombotic effect from the simultaneous inhibition of thrombin and factor Xa. Blood Coagul Fibrin. 2010;21(2):128-34.

42. Monagle P, Berry L, O'Brodovich H, Andrew M, Chan A. Covalent heparin cofactor II-heparin and heparin cofactor II-dermatan sulfate complexes. Characterization of novel anticoagulants. J Biol Chem. 1998;273(50):33566-71.

43. Van Deerlin VM, Tollefsen DM. The N-terminal acidic domain of heparin cofactor II mediates the inhibition of alpha-thrombin in the presence of glycosaminoglycans. J Biol Chem. 1991;266(30):20223-31. 
44. Ewing MM, Karper JC, Sampietro ML, de Vries MR, Pettersson K, Jukema JW, Quax PH. Annexin A5 prevents post-interventional accelerated atherosclerosis development in a dose-dependent fashion in mice. Atheroscler. 2012;221(2):333-40.

45. Andree HA, Stuart MC, Hermens WT, Reutelingsperger CP, Hemker HC, Frederik PM, Willems GM. Clustering of lipid-bound annexin $V$ may explain its anticoagulant effect. J Biol Chem. 1992;267(25):17907-12.

46. Brown EM, Gamba G, Riccardi D, Lombardi M, Butters R, Kifor O, Sun A, Hediger MA, Lytton J, Hebert SC. Cloning and characterization of an extracellular $\mathrm{Ca}(2+)$-sensing receptor from bovine parathyroid. Nat. 1993; 366(6455):575-80

47. Smajilovic S, Tfelt-Hansen J. Novel role of the calcium-sensing receptor in blood pressure modulation. Hypertens. 2008;52(6):994-1000.

48. Davies T, Schepelmann M, Brennan S, Yarova P, Chang W, Bikle D, Richards W, Ward DT, Canfield AE, Edwards D, et al. An investigation of the role of calcimimetics in a murine model of targeted deletion of the calciumsensing receptor, CaSR, from vascular smooth muscle cells (SM22 alpha $x \mathrm{fl}$ CaSR). Bone. 2012;51(6):S24-5.

49. Verhaar MC, Strachan FE, Newby DE, Cruden NL, Koomans HA, Rabelink TJ, Webb DJ. Endothelin-a receptor antagonist-mediated vasodilatation is attenuated by inhibition of nitric oxide synthesis and by endothelin-B receptor blockade. Circ. 1998;97(8):752-6.

50. Merkus D, Houweling B, Mirza A, Boomsma F, van den Meiracker AH, Duncker DJ. Contribution of endothelin and its receptors to the regulation of vascular tone during exercise is different in the systemic, coronary and pulmonary circulation. Cardiovasc Res. 2003;59(3):745-54.

51. Chavakis T, Boeckel N, Santoso S, Voss R, Isordia-Salas I, Pixley RA, Morgenstern E, Colman RW, Preissner KT. Inhibition of platelet adhesion and aggregation by a defined region (Gly-486-Lys-502) of high molecular weight kininogen. J Biol Chem. 2002;277(26):23157-64.

52. Chao J, Chao L. Kallikrein-kinin in stroke, cardiovascular and renal disease. Exp Physiol. 2005;90(3):291-8.

53. Shou QY, Pan YM, Xu XP, Xu JQ, Wang DJ, Ling Y, Chen ML. Salvianolic acid $\mathrm{B}$ possesses vasodilation potential through $\mathrm{NO}$ and its related signals in rabbit thoracic aortic rings. Eur J Pharmacol. 2012;697(1-3):81-7.

54. Gregori C, Guillet-Deniau I, Girard J, Decaux JF, Pichard AL. Insulin regulation of glucokinase gene expression: evidence against a role for sterol regulatory element binding protein 1 in primary hepatocytes. FEBS Lett. 2006;580(2): 410-4.

55. Matone A, Derlindati E, Marchetti L, Spigoni V, Dei Cas A, Montanini B, Ardigo D, Zavaroni I, Priami C, Bonadonna RC. Identification of an early transcriptomic signature of insulin resistance and related diseases in lymphomonocytes of healthy subjects (vol 12, e0182559, 2018). PLoS One. 2019;14(l):e0182599.

56. Clough MH, Schneider DJ, Sobel BE, White MF, Wadsworth MP, Taatjes DJ. Attenuation of accumulation of neointimal lipid by pioglitazone in mice genetically deficient in insulin receptor substrate-2 and apolipoprotein E. J Histochem Cytochem. 2005;53(5):603-10.

57. Babaev VR, Ishiguro H, Ding L, Yancey PG, Dove DE, Kovacs WJ, Semenkovich CF, Fazio S, Linton MF. Macrophage expression of peroxisome proliferator-activated receptor-alpha reduces atherosclerosis in low-density lipoprotein receptor-deficient mice. Circ. 2007;116(12):1404-12.

58. Wang QY, Li C, Zhang Q, Wang YY, Shi TJ, Lu LH, Zhang Y, Wang Y, Wang $W$. The effect of Chinese herbs and its effective components on coronary heart disease through PPARs-PGC1 alpha pathway. Bmc Complem Altern M. 2016;16(1):514

59. Krishnadas DK, Li W, Kumar R, Tyrrell LJ, Agrawal B. In vitro activation and differentiation of naive CD4(+) and CD8(+) T cells into HCV Core- and NS3specific armed effector cells: a new role for CD4(+) T cells. Cell Immunol. 2009;259(2):141-9.

60. Huntington ND, Tarlinton DM. CD45: direct and indirect government of immune regulation. Immunol Lett. 2004;94(3):167-74.

61. Wada T, Sakakibara Y, Nishimura R, Toma T, Ueno Y, Horita S, Tanaka T, Nishi $M$, Kato K, Yasumi T, et al. Down-regulation of CD5 expression on activated CD8(+) T cells in familial hemophagocytic lymphohistiocytosis with perforin gene mutations. Hum Immunol. 2013;74(12):1579-85.

62. Wang $H$, Zeng $X$, Fan ZG, Lim B. RhoH modulates pre-TCR and TCR signalling by regulating LCK. Cell Signal. 2011;23(1):249-58.

63. Perez-Villar JJ, Whitney GS, Sitnick MT, Dunn RJ, Venkatesan S, O'Day K, Schieven GL, Lin TA, Kanner SB. Phosphorylation of the linker for activation of T-cells by Itk promotes recruitment of Vav. Biochem. 2002;41(34):10732-40.
64. Liu XL, Shan WJ, Jia LJ, Yang X, Zhang JJ, Wu YR, Xu FZ, Li JN. Avian leukosis virus subgroup $\mathrm{J}$ triggers caspase-1-mediated inflammatory response in chick livers. Virus Res. 2016;215:65-71.

65. Santos-Gallego CG, Picatoste B, Badimon JJ. Pathophysiology of Acute Coronary Syndrome. Curr Atheroscler Rep. 2014;16(4):401.

66. Sun JS, Sukhova GK, Wolters PJ, Yang M, Kitamoto S, Libby P, MacFarlane LA, Clair JMS, Shi GP. Mast cells promote atherosclerosis by releasing proinflammatory cytokines. Nat Med. 2007;13(6):719-24.

67. Chien MY, Chuang CH, Chern CM, Liou KT, Liu DZ, Hou YC, Shen YC. Salvianolic acid a alleviates ischemic brain injury through the inhibition of inflammation and apoptosis and the promotion of neurogenesis in mice. Free Radical Bio Med. 2016;99:508-19.

68. Wallace S, Guo DC, Regalado E, Mellor-Crummey L, Bamshad M, Nickerson DA, Dauser R, Hanchard N, Marom R, Martin E, et al. Disrupted nitric oxide signaling due to GUCY1A3 mutations increases risk for moyamoya disease, achalasia and hypertension. Clin Genet. 2016;90(4):351-60.

69. Mittendorf J, Weigand S, Alonso-Alija C, Bischoff E, Feurer A, Gerisch M, Kern A, Knorr A, Lang D, Muenter K, et al. Discovery of Riociguat (BAY 63-2521): a potent, Oral stimulator of soluble Guanylate Cyclase for the treatment of pulmonary hypertension. ChemMedChem. 2009;4(5):853-65.

70. Li Q, Shen L, Wang Z, Jiang HP, Liu LX. Tanshinone IIA protects against myocardial ischemia reperfusion injury by activating the PI3K/Akt/mTOR signaling pathway. Biomed Pharmacother. 2016;84:106-14.

71. Huang Q, Wu Y, Qin C, He WW, Wei X. Phylogenetic and structural analysis of the phospholipase A2 gene family in vertebrates. Int J Mol Med. 2015; 35(3):587-96.

72. Jung JH, Kumar K, Lee HY, Park Yl, Cho HT, Ryu SB. Translocation of phospholipase a(2)alpha to apoplasts is modulated by developmental stages and bacterial infection in Arabidopsis. Front Plant Sci. 2012;18(3):126.

73. Gesquiere L, Cho W, Subbaiah PV. Role of group Ila and group V secretory phospholipases a(2) in the metabolism of lipoproteins. Substrate specificities of the enzymes and the regulation of their activities by sphingomyelin. Biochem. 2002;41(15):4911-20.

74. Talmud PJ, Holmes MV. Deciphering the causal role of sPLA2s and LP-PLA2 in coronary heart disease. Arterioscl Throm Vas. 2015;35(11):2281-9.

75. Theken KN, Schuck RN, Edin ML, Tran B, Ellis K, Bass A, Lih FB, Tomer KB, Poloyac SM, Wu MC et al: Evaluation of cytochrome P450-derived eicosanoids in humans with stable atherosclerotic cardiovascular disease. Atheroscler 2012, 222(2):530-536.

76. Jia LQ, Song N, Yang GL, Ma YX, Li XT, Lu R, Cao HM, Zhang N, Zhu ML, Wang JY, et al. Effects of Tanshinone IIA on the modulation of miR-33a and the SREBP-2/Pcsk9 signaling pathway in hyperlipidemic rats. Mol Med Rep. 2016;13(6):4627-35.

77. Li HS, Pauza CD. Critical roles for Akt kinase in controlling HIV envelopemediated depletion of CD4 T cells. Retrovirology. 2013;10.

78. Laird RM, Hayes SM. Roles of the Src Tyrosine Kinases Lck and Fyn in Regulating gamma delta TCR Signal Strength. PLoS One. 2010;5(I):e8899.

79. San Jose E, Sahuquillo AG, Bragado R, Alarcon B. Assembly of the TCR/CD3 complex: CD3 epsilon/delta and CD3 epsilon/gamma dimers associate indistinctly with both TCR alpha and TCR beta chains. Evidence for a double TCR heterodimer model. Eur J Immunol. 1998;28(1):12-21.

80. Torres PS, Alcover A, Zapata DA, Arnaud J, Pacheco A, Martin-Fernandez JM, Villasevil EM, Sanal O, Regueiro JR. TCR dynamics in human mature T lymphocytes lacking CD3 gamma. J Immunol. 2003;170(12):5947-55.

81. Pelanda R, Braun U, Hobeika E, Nussenzweig MC, Reth M. B cell progenitors are arrested in maturation but have intact VDJ recombination in the absence of Ig-alpha and Ig-beta. J Immunol. 2002;169(2):865-72.

82. Cao MD, Chen ZD, Xing Y. Gamma irradiation of human dendritic cells influences proliferation and cytokine profile of $T$ cells in autologous mixed lymphocyte reaction. Cell Biol Int. 2004;28(3):223-8.

83. Li HZ, Lu YH, Huang GS, Chen Q, Fu Q, Li ZL. Tanshinone II a inhibits dendritic cell-mediated adaptive immunity: potential role in antiatherosclerotic activity. Chin J Integr Med. 2014;20(10):764-9.

\section{Publisher's Note}

Springer Nature remains neutral with regard to jurisdictional claims in published maps and institutional affiliations. 